\title{
Intelligent predetermined control method for sinusoidal temperature testing on a cylindrical environmental chamber
}

\author{
San-Shan HUNG*, Yung-Han CHEN** and Albert Chin-Yuh LIN*** \\ *Department of Automatic Control Engineering, Feng Chia University, Taichung 40724, Taiwan \\ ${ }^{* *}$ Ph.D. Program of Electrical and Communications Engineering, Feng Chia University, Taichung 40724, Taiwan \\ E-mail: oyung750531@gmail.com \\ ${ }^{* * *}$ Gong Bu Design Company, Ltd, Taichung 40750, Taiwan
}

Received: 13 March 2018, Revised: 20 August 2018, Accepted: 13 September 2018

\begin{abstract}
The Intelligent Predetermined Control Method (IPCM) aims to predetermine the requirements of programmed changes in the test chamber, which differentiates from the gain-scheduling PID (GS-PID) control method in accordance with dry and wet bulb temperature errors. The IPCM consists of a scheduling of optimal control path, a determination of the heat and water vapor mass flow rates along the path, an estimation of heat loss from walls of chamber, and a compensation for unexpectedness with a fixed-gain PID controller. In order to verify the feasibility of the sinusoidal temperature test by using the IPCM, a cylindrical test chamber with independent flow loops was designed, and it equips a precise heating system and a variable refrigerant flow (VRF) cooling system with a variable-frequency drive (VFD) compressor. This paper uses process models with nonlinear gain to identify the models of the heating and cooling systems individually. An experiment was performed by using a $5-45{ }^{\circ} \mathrm{C}$ sine wave excitation. The results show that the temperature in the chamber closely tracks along the programmed sine wave excitation with less than $\pm 0.25^{\circ} \mathrm{C}$ of errors in almost entire cycles, which indicates that the IPCM is able to advance the chamber testing into the acceleration test beyond the ordinary step and ramp excitation.
\end{abstract}

Keywords : Intelligent predetermined control method, Control path scheduling, Sinusoidal temperature control, Cylindrical environmental test chamber, Independent flow loops

\section{Nomenclature}

$C$

$P$

$P_{v s}$

$\dot{Q}$

$R$

$R_{d a}$

$T$

$T_{K}$

$V$

$c_{p}$

$h$

$\dot{m}_{d a}$

$m_{d a}$

$t$
Equivalent heat capacitance, $\mathrm{J} /{ }^{\circ} \mathrm{C}$

Total pressure, $\mathrm{kPa}$

Water vapor saturation pressure, $\mathrm{kPa}$

Heat flow rate, $\mathrm{W}$

Equivalent heat resistance, ${ }^{\circ} \mathrm{C} / \mathrm{W}$

Gas constant for dry air, $\mathrm{J} /(\mathrm{kg} \cdot \mathrm{K})$

Celsius temperature, ${ }^{\circ} \mathrm{C}$

Absolute temperature, $\mathrm{K}$

Air volume, $\mathrm{m}^{3}$

Isobaric mass heat capacity, $\mathrm{J} /(\mathrm{kg} \cdot \mathrm{K})$

Specific enthalpy of moist air, $\mathrm{kJ} / \mathrm{kg}$

Mass flow rate for dry air, $\mathrm{kg} / \mathrm{s}$

Dry air mass, $\mathrm{kg}$

Time, $\mathrm{s}$

$\begin{array}{ll}v_{d a} & \text { Dry air specific volume, } \mathrm{m}^{3} / \mathrm{kg} \\ \phi & \text { Relative humidity, } \% \\ \omega & \text { Humidity ratio, } \mathrm{kg} / \mathrm{kg} \\ \text { Subscripts } & \\ \text { act } & \text { Actuator } \\ \text { cha } & \text { Chamber } \\ \text { env } & \text { Environment } \\ i & i \text {-th } \text { state } \\ i+1 & i+1 \text {-th } \text { state } \\ \text { in } & \text { Inlet pipe } \\ \text { loss } & \text { Loss } \\ \text { out } & \text { Outlet pipe } \\ \text { set } & \text { Set point } \\ \text { wall } & \text { Wall }\end{array}$




\section{Introduction}

The ordinary temperature and humidity test chamber is structured as shown in Fig. 1. The operating principle is based upon a balanced temperature and humidity control system and devices such as a heating system, a humidifying system, and a refrigerant system with a fixed speed compressor, the temperature and humidity of a workspace can be controlled for step programs or temperature gradient programs. The system control block diagram using gain-scheduling PID (GS-PID) control method is shown in Fig. 2. According to the dry bulb and wet bulb temperatures, the system determines the working conditions and selects the appropriate set of PID control parameters from multiple predefined sets, which are designed for a wide range of operating conditions. However, the PID parameters of a GS-PID controller must be tuned for different temperature and relative humidity ranges without a load prior to operating the machine. The process of tuning the PID parameters is tedious, and it is sometimes difficult to schedule parameters in neighboring control regions.

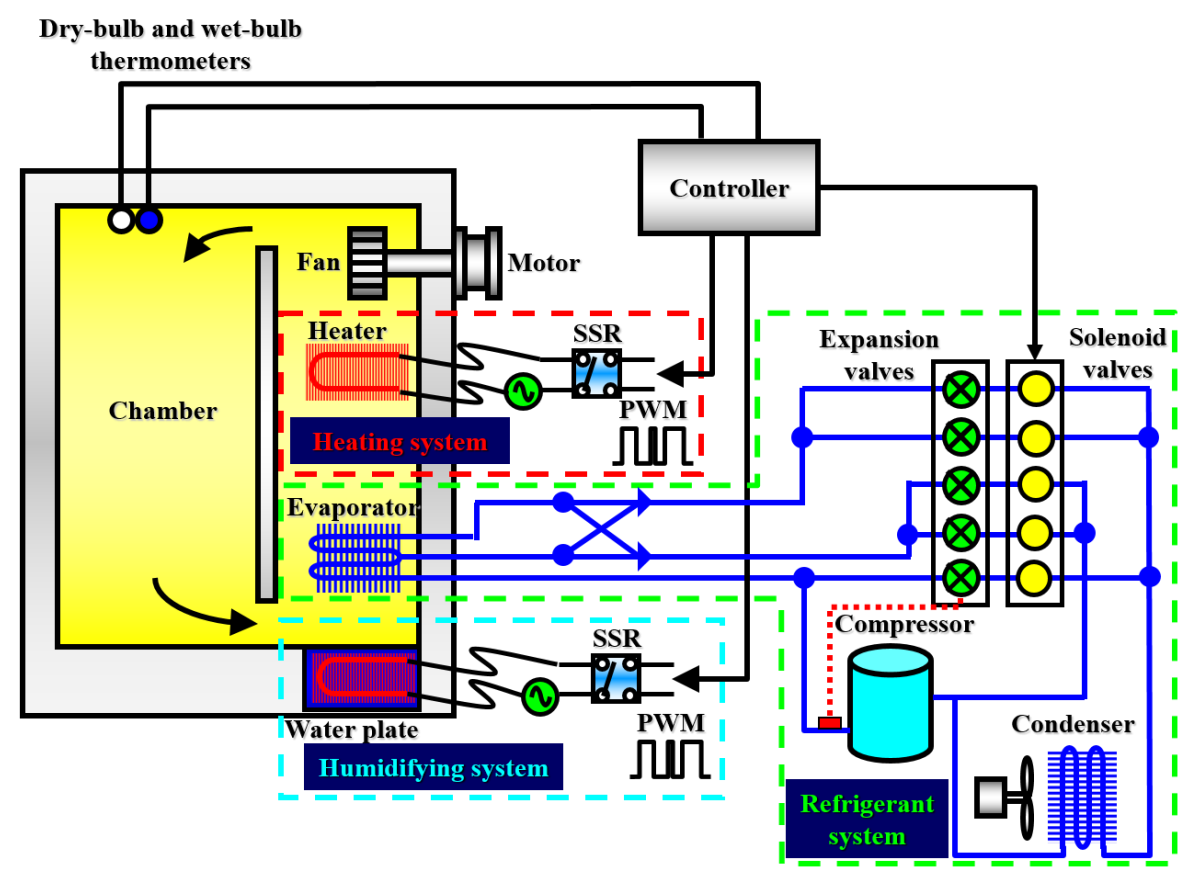

Fig. 1 Structural diagram of a traditional environmental chamber.

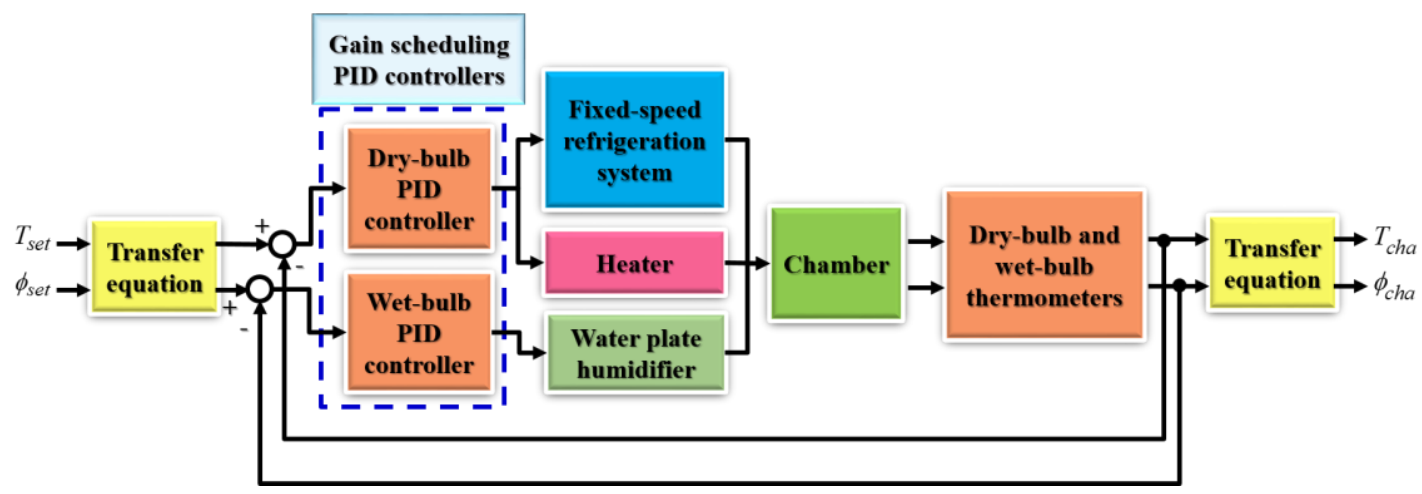

Fig. 2 Control block diagram of a traditional environmental chamber.

Many researchers have been devoted into solving the nonlinear and highly coupled of temperature and relative humidity of air in test chamber. In recent years, most techniques of temperature and humidity control can be sorted by methods such as PID control, Internal Model Control (IMC), Fuzzy Logic, Adaptive Control, Artificial Neural Network (ANN), Model Predictive Control (MPC), and others. However, the PID controllers are mostly applied in the Linear 
Time-invariant (LTI) system, many improved methods were introduced, such as deriving a dynamic model with a tuning PID controller by Ziegler-Nichols rule to control an HVAC system (Tashtoush et al., 2005), decoupling the multiple-input multiple-output (MIMO) dynamics of the temperature and humidity control system into two single-input single-output (SISO) systems (Huang et al., 2007), using the Internal Model Control with PID controller to solve the coupling problem (Zeng and Yu, 2014), and presenting a multivariable cascade control with the non-interacting control law and PD control to decouple the control temperature and relative humidity (Rentel-Gomez and Velez-Reyes, 2001). Related with artificial intelligent region, Fuzzy Logic is known as for controlling the uncertainty, inaccuracy, and difficult modeling system, such as Takagi-Sugeno fuzzy model to control the temperature and humidity in greenhouses (Nachidi et al., 2006), and Fuzzy Logic combined with PID controller to control the air-conditioning system (Yordanova et al., 2015) and with direct adaptive control to control the greenhouse climate (Su et al., 2016). There are some researchers use the ANN-based controller for air conditioning systems (Li et al., 2013; Li et al., 2015; Yang et al., 2016). Concerning model predictive control (MPC), the MPCs are based on the system identification technique to build the linear or nonlinear empirical models of dynamics systems, and they can optimize the current time slot and anticipate future events, so some researchers use the MPC in the complex dynamic systems such as buildings (Oldewurtel et al., 2014; Sturzenegger et al., 2016) and hybrid electric vehicles (Lopez-Sanz et al., 2017).

Although these control methods are effective, but complicated for the environmental test chamber in the wide range of operating conditions. This paper presents a new control algorithm, which is called the Intelligent Predetermined Control Method (IPCM), to substitute for the tedious GS-PID controllers, avoid the gain scheduling deficiency, and obtain more precise controlled results.

\section{Intelligent Predetermined Control Method}

The idea of IPCM is to predetermine the path and estimate how much heat and water vapor mass flow rates are required on the path. In practice, the actuators only need to provide the estimated heat and water vapor mass flow rates for changing the temperature and relative humidity along the planned path.

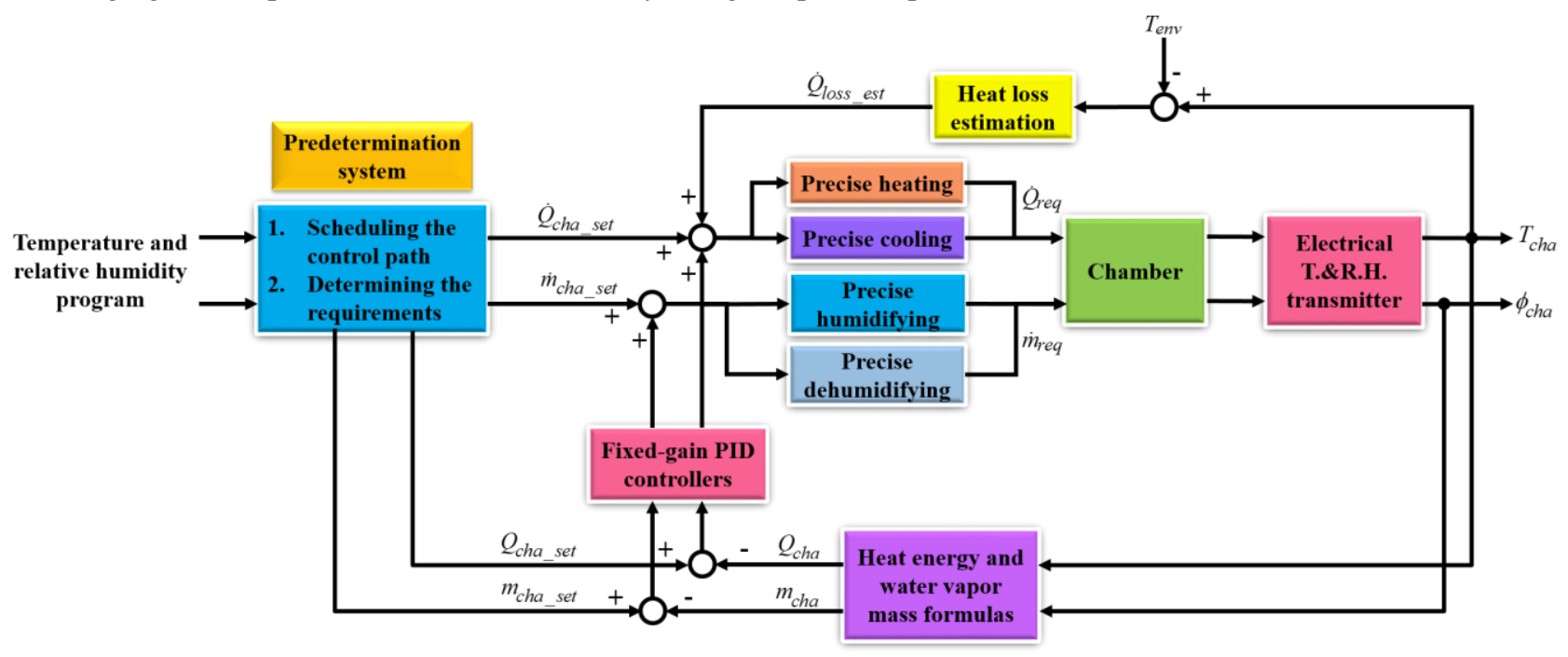

Fig. 3 Control block diagram of the IPCM

The control block diagram of IPCM is shown in Fig. 3. When inputs a temperature and relative humidity program, the predetermination system will plan a control path that comprises many states based on the program type as well as the temperature and relative humidity tolerance. Then, the heat and water vapor mass for each state on the path are calculated, and the required heat and water vapor flow rates are determined for the interval between each successive state. At this point, the predetermination part is complete, and the control implementation begins. The precise actuators provide the necessary heat flow rate and water vapor mass flow rate for the test chamber mainly based on the requirements of the control path and the heat loss from the wall of the chamber. The electronic temperature and relative humidity transmitters return the measured temperature and relative humidity for checking the stored heat energy and water vapor mass in the chamber. In addition, the fixed-gain PID controller in the control block diagram is used to 
compensate for the errors in the heat loss estimation, models of actuators, and other unpredictable errors. Consequently, the temperature and relative humidity are guaranteed to be within the error tolerance.

\subsection{Scheduling Sine Wave Temperature Control Path}

The scheduling of sine wave temperature depends on the tolerance as a constraint to calculate the next temperature point corresponding to the time until the entire period has been completed. As shown in Fig. 4, the black line is the theoretical sine wave, and the red and light blue lines above and below the theoretical sine wave are the tolerance lines for the temperature precision. Without going outside of the tolerance lines, the current temperature point is used to derive the position and time of the next temperature point, as shown with the orange stair-step curve. Finally, the deep blue line is the scheduled sine wave control path. Furthermore, the tolerance of temperature can be shrunk if the actuators provide the heat flow rate precisely, consequently, one of the key techniques of the IPCM is to design the precise heating and cooling systems.

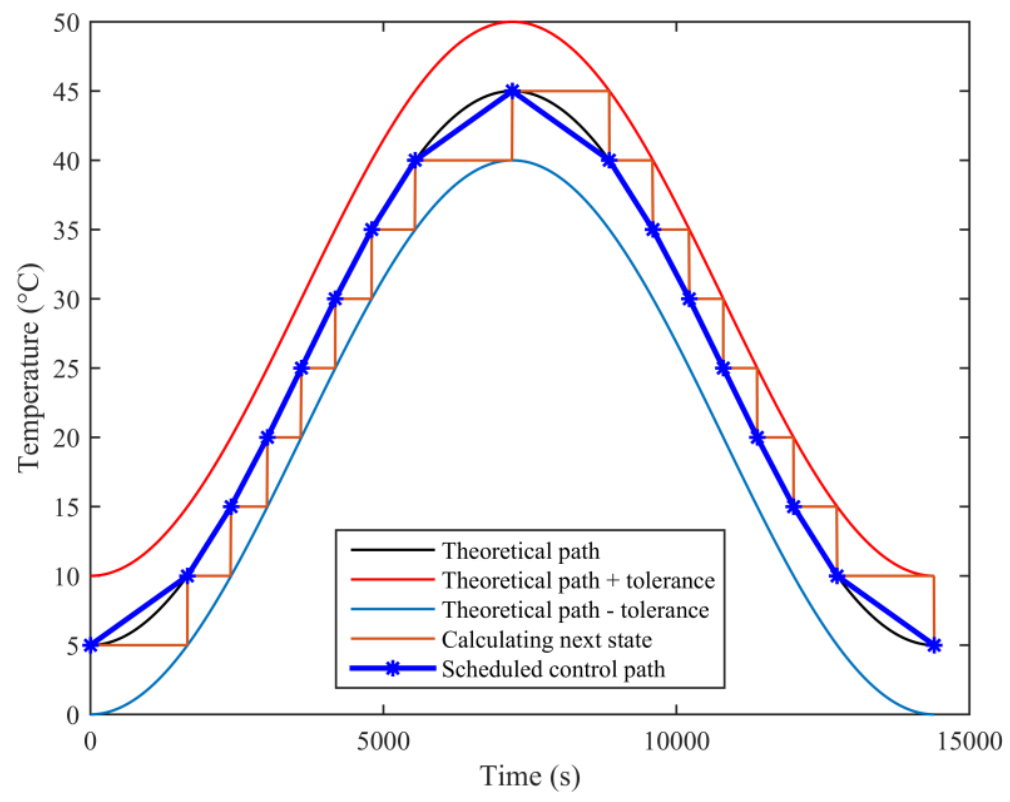

Fig. 4 Scheduling method of the sine wave temperature

\subsection{Predetermining the Required Heat Flow Rate}

After obtaining the control path, the predetermination system must immediately calculate the required heat flow rate to move from one temperature point to another. Figure 5 is the energy flow diagram of the test chamber, and the heat transfer model of this chamber is assumed by using resistance-capacitance equivalent model, shown as Fig. 6.

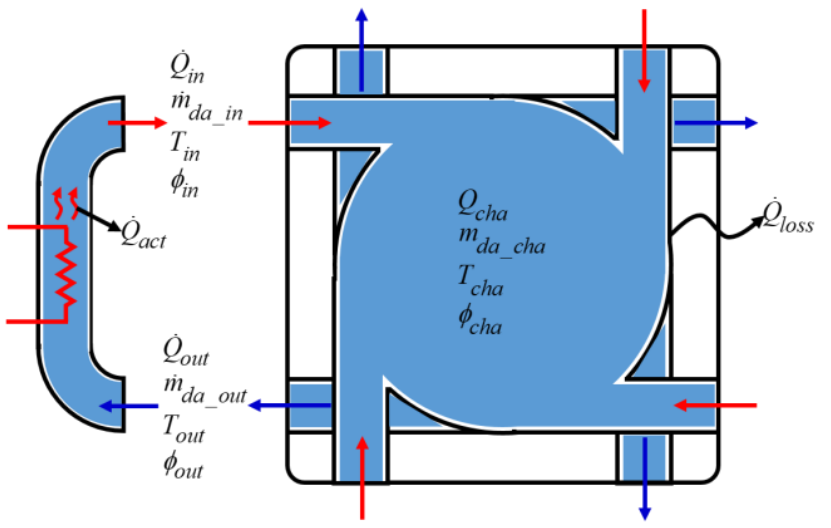

Fig. 5 Energy flows of cylindrical chamber

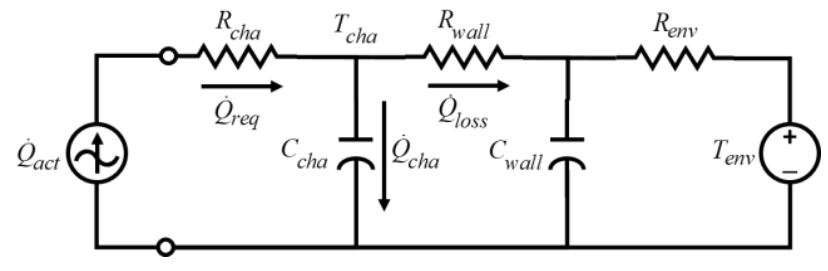

Fig. 6 RC equivalent model for heat transfer 
The required heat flow rate $\dot{Q}_{\text {req }}$ is sum of the stored heat flow rate $\dot{Q}_{c h a}$ and the heat loss $\dot{Q}_{\text {loss }}$ shown as Eq. (1). The heat loss is caused by the gradient between the chamber temperature $T_{\text {cha }}$ and the environmental temperature $T_{\text {env }}$, and the equivalent resistance $R_{\text {wall }}$ and capacitance $C_{\text {wall }}$ are affected by the dimensions of heat transfer and materials of the wall. For this reason, the estimation of heat loss is built by an experiment in this paper.

$$
\dot{Q}_{r e q}=\dot{Q}_{\text {cha }}+\dot{Q}_{\text {loss }}
$$

The stored heat flow rate $\dot{Q}_{\text {cha_i }}$ for changing the temperature from the $i$-th state to the $i+1$-th state is shown in Eq. (2). It is the product of the dry air mass $m_{d a_{-} c h a_{-} i}$ and the difference in enthalpy between the $i$-th state $h_{c h a_{-} i}$ and the $i+1$-th state $h_{c h a_{-} i+1}$; then, the change of heat energy is divided by the time $\Delta t_{i}=t_{i+1}-t_{i}$.

$$
\dot{Q}_{c h a_{-} i}=\frac{\Delta Q_{c h a_{-} i}}{\Delta t_{i}}=\frac{m_{d a_{-} c h a_{-} i}\left(h_{c h a_{-} i+1}-h_{c h a_{-} i}\right)}{t_{i+1}-t_{i}}=\frac{V_{c h a}}{v_{d a_{-} c h a_{-} i}} \frac{h_{c h a_{-} i+1}-h_{c h a_{-} i}}{t_{i+1}-t_{i}}
$$

In addition, the formulas for thermodynamics of moist air and water, which were developed by Hyland and Wexler (1983a, 1983b). The specific volume $v_{d a_{-} c h a}$ of dry air is given by Eq. (3), and the specific enthalpy $h_{c h a}$ can be written as Eq. (4). Then, the humidity ratio is involved in Eq. (3) and Eq. (4), determined by relative humidity $\phi_{c h a}$ and water vapor saturation pressure $P_{v s_{-} c h a}$ as shown in Eq. (5). The water vapor saturation pressure over liquid water for the temperature range of $0-200{ }^{\circ} \mathrm{C}$ is given by Eq. (6), where $C_{1}, C_{2}, C_{3}, C_{4}, C_{5}$, and $C_{6}$ are coefficients.

$$
\begin{aligned}
& v_{d a_{-} c h a}=\frac{R_{d a} T_{K_{-} c h a}\left(1+1.608 \omega_{c h a}\right)}{P} \\
& h_{c h a}=c_{p} T_{c h a}+\omega_{c h a}\left(2501+1.805 T_{\text {cha }}\right) \\
& \omega_{\text {cha }}=0.622 \frac{\phi_{c h a} P_{v s_{-} c h a}}{P-\phi_{c h a} P_{v s_{-} c h a}} \\
& P_{v s_{-} c h a}=\exp \left(C_{1} / T_{K_{-} c h a}+C_{2}+C_{3} T_{K_{-} c h a}+C_{4} T_{K_{-} c h a}{ }^{2}+C_{5} T_{K_{-} c h a}{ }^{3}+C_{6} \ln T_{K_{-} c h a}\right)
\end{aligned}
$$

Upon these formulas, the heat energy set-point of test chamber for sinusoidal temperature testing is determined by the temperature of the scheduled sine wave and the measured relative humidity from the chamber. Besides, the heat flow rate provided by the actuator is the difference in the heat flow rate between the inlet pipe $\dot{Q}_{i n_{-} i}$ and outlet pipe $\dot{Q}_{\text {out } \_i}$, as shown in Eq. (7). Assuming that the inlet dry air mass flow rate of the actuator is equal to the outlet one, $\dot{m}_{d a_{-} i n_{-} i}=\dot{m}_{d a_{-} o u t_{-} i}$, and the equation is rewritten as Eq. (8).

$$
\begin{aligned}
& \dot{Q}_{\text {req_i }}=\dot{Q}_{\text {in_i } i}-\dot{Q}_{\text {out }_{-} i}=\dot{m}_{d a_{-} i n_{-} i} h_{\text {in } \_i}-\dot{m}_{d a_{-} \text {out } \_i} h_{\text {out } \_i} \\
& \dot{Q}_{\text {req_i }}=\dot{m}_{d a_{-} i n_{-} i}\left(h_{\text {in_ }_{-} i}-h_{\text {out } \_}\right)
\end{aligned}
$$

A precise heating and cooling system can be designed according to the required heat flow rate. Equation (8) reveals that obtaining the air mass flow rate and enthalpy at the actuator inlet and outlet is sufficient to identify the characteristics of the actuator.

\section{Design a Cylindrical Chamber with Independent Flow Loops}

Since the airflow produced by axial fans in a cuboid test chamber will create dead corners in flow streams, a cylindrical test chamber is designed to improve the airflow. The airflow from the axial fan can move along the chamber walls, significantly reducing instances of dead corners, producing unobstructed circulation, and improving the uniformity of the temperature and relative humidity. Furthermore, to simultaneously solve the problem of interference from the actuators in the same airflow loop, the concept of the independent flow loops is used from the previous study 
(Hung et al., 2015). In addition, to prevent affecting the airflow from the actuator into the test chamber, the inlet and outlet pipes must be tailored as tangential to the airflow shown in Fig. 7. The red arrows indicate the inlet pipes, and the blue ones are the outlet pipes. A computational fluid dynamics (CFD) software, SOLIDWORKS Flow Simulation, was used to confirm the airflow lines in the cylindrical test chamber. The inlet and outlet volume flow rates of one of four flow loops are assumed as $0.006 \mathrm{~m}^{3} / \mathrm{s}$, the angular velocity of axial fan blades is $1200 \mathrm{RPM}$, and the environment pressure and the gravity are considered. The analysis type is time-dependent from 0 to 1200 seconds with 1 second of time step. The simulation results shown in Fig. 8 exhibits the flow lines are smooth with no unusual eddies.

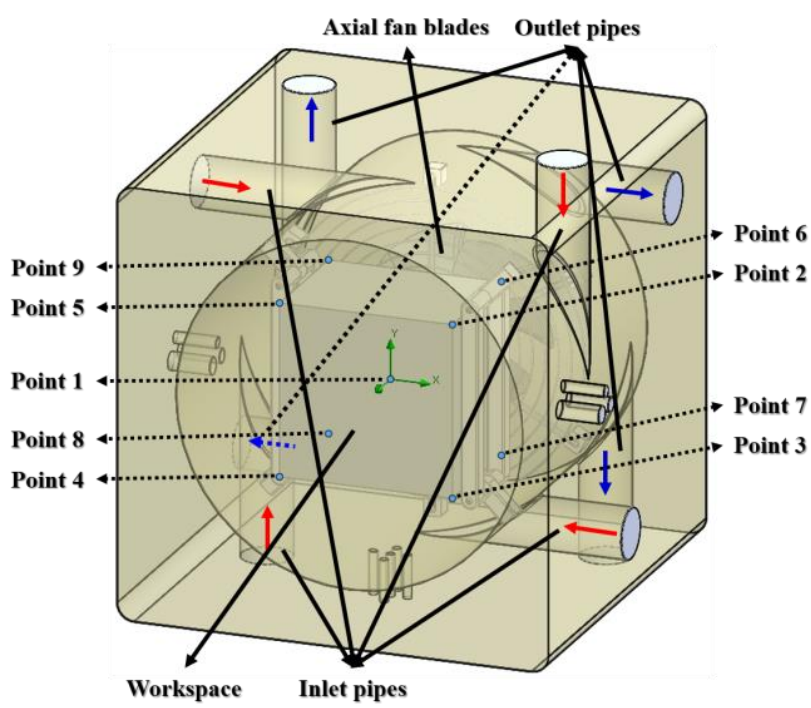

Fig. 7 Structure of the cylindrical chamber

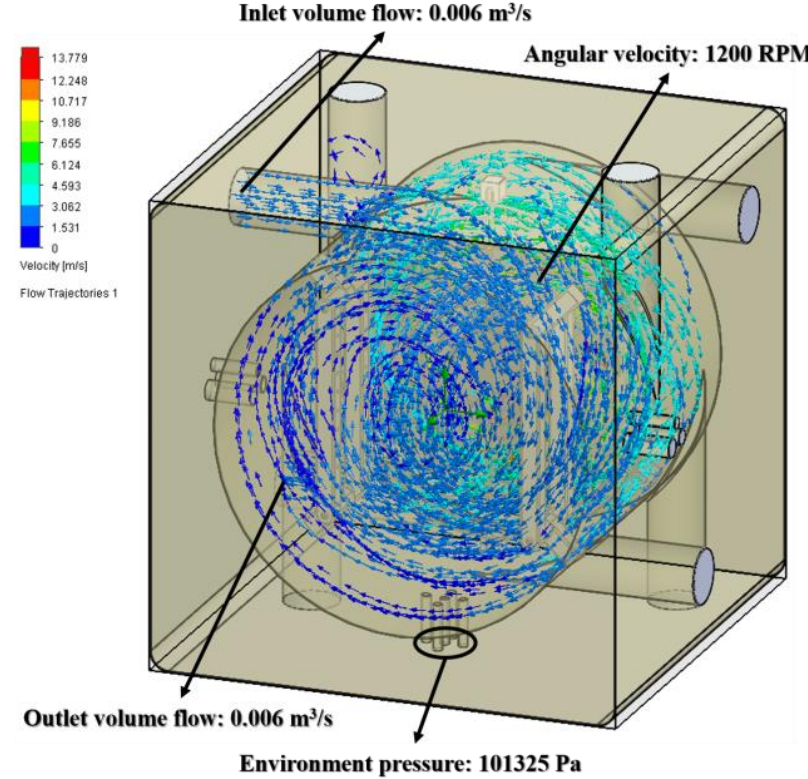

Fig. 8 CFD result of the cylindrical chamber

The temperature field uniformity in the workspace is evaluated with nine measuring points (Ishida, 2007). The JTM standards define the working space at the space excluding 1/10 of distance from inner walls, and the 9 measuring points are defined as the chamber center and 8 corners of working space. However, the distance from the inner walls must be specified as a minimum value according to the volume of each test chamber. Consequently, the dimension of the cylindrical test chamber workspace is $0.2 \mathrm{~m}$ wide by $0.2 \mathrm{~m}$ high by $0.15 \mathrm{~m}$ deep and nine measuring points are shown in Fig. 7. After testing with a $5-45^{\circ} \mathrm{C}$ temperature ramp program, the temperatures of the nine measuring points are shown in Fig. 9. The mean and standard deviation of the nine temperature measurements at each sampling time are calculated to obtain the mean and standard deviation curves plotted against time in Fig. 10; the top blue curve is the dynamic mean, whereas the bottom red curve is the dynamic standard deviation. The standard deviation maintains within $0.6{ }^{\circ} \mathrm{C}$ at $5{ }^{\circ} \mathrm{C}$ steady state range, and gradually increases up to $1.7^{\circ} \mathrm{C}$ as the temperature reaching $45^{\circ} \mathrm{C}$. After that it then down to $1.5{ }^{\circ} \mathrm{C}$ when the temperature stabilized at $45^{\circ} \mathrm{C}$. The plots of Fig. 10 review that the cylindrical chamber is good in temperature uniformity.

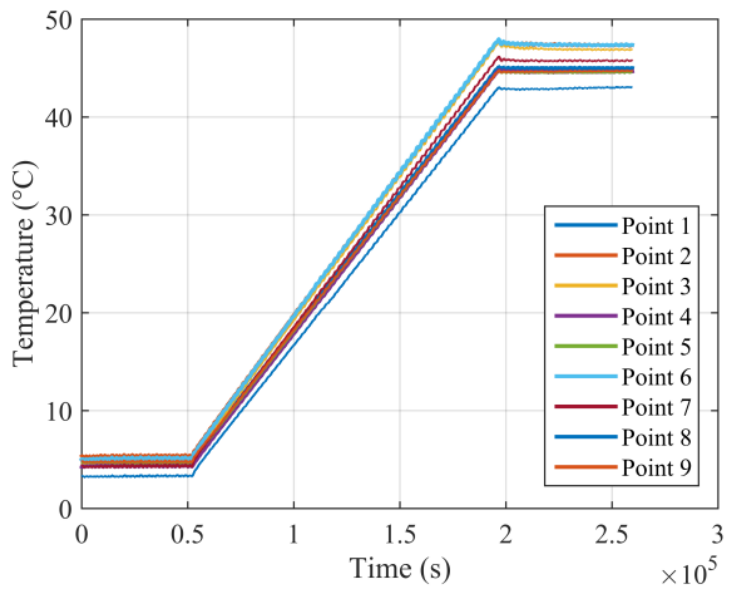

Fig. 9 Temperatures of the measured points
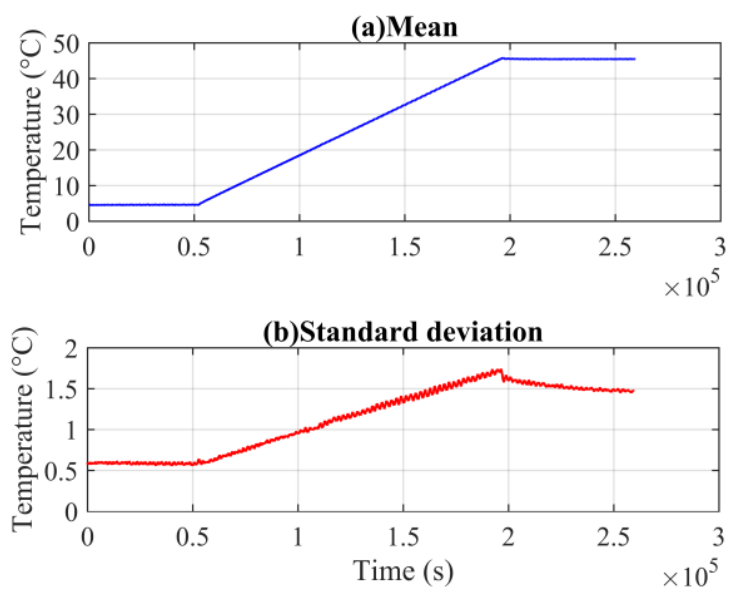

Fig. 10 Mean and standard deviation of experiment data 


\subsection{Precise Heating System}

To refer the former designed precise heating system (Hung et al., 2015), a new-designed precise heating system with a hot wire heater is shown in Fig. 11. The structure is more compact and better energy efficiency. The heating system packs a thyristor power regulator to regulate the duty cycle of the power, precisely controlling the output heat flow rate of the heating system. To modeling the heating system, system identification was performed to characterize the heating system. An experiment was performed to obtain the heat flow data generated by the precise heating system through specific commands. As shown in Fig. 12, the blue line is the control signal, and the red line is the response of the heat flow rate.

The heat flow rate and control signal is obvious with nonlinear relationship; the gain curve is depicted in Fig. 13. Assume that the model of the heating system is a first-order process model, the system identification toolbox of MATLAB gives the system parameters and response as shown in Fig. 14. The time constant is 83.37 seconds, which signifies that the heating system reaches the final value of response in five times the time constant, 416.85 seconds.

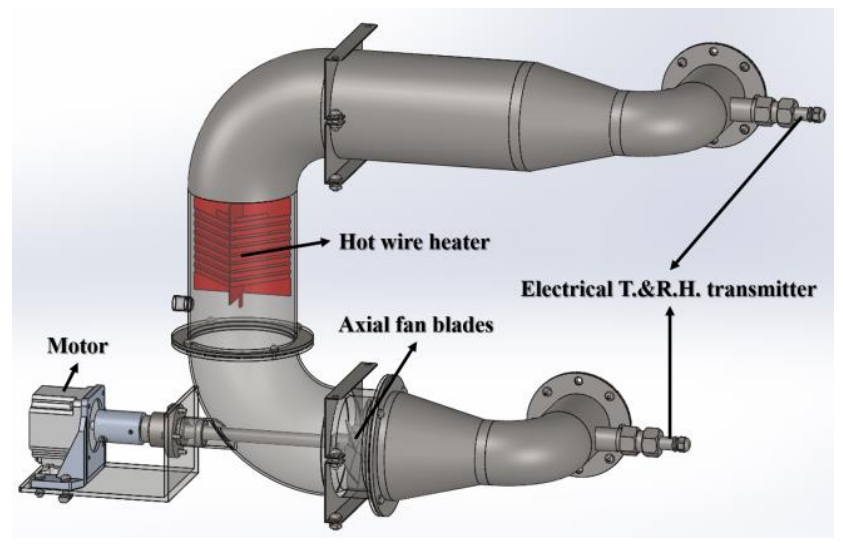

Fig. 11 Structure of precise heating system

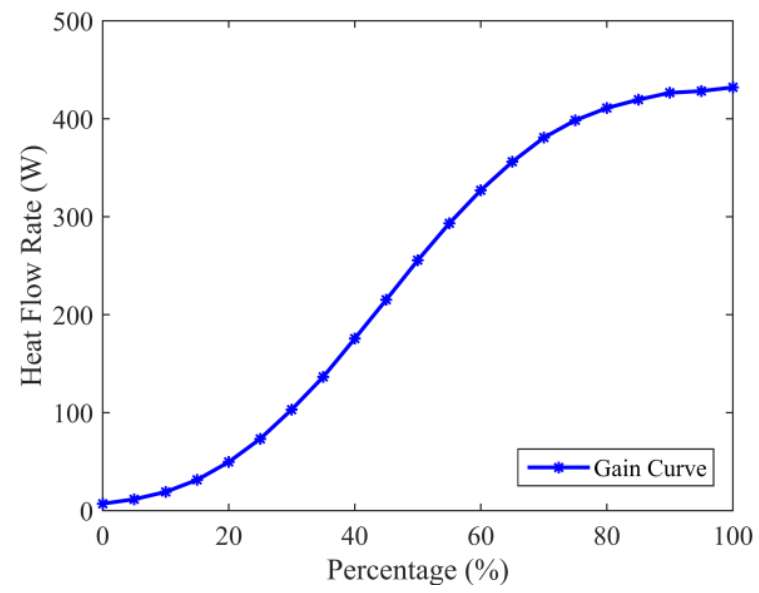

Fig. 13 Nonlinear gain curve of the precise heating system

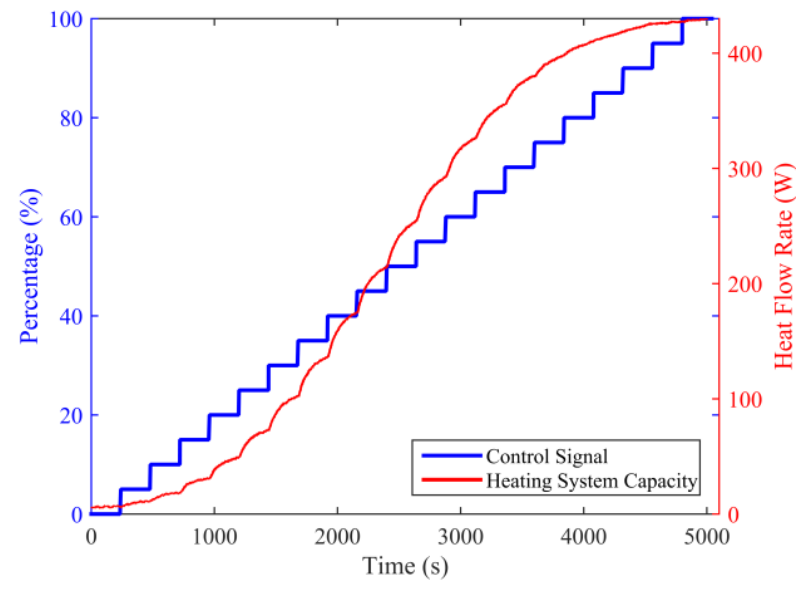

Fig. 12 Identification data of the precise heating system

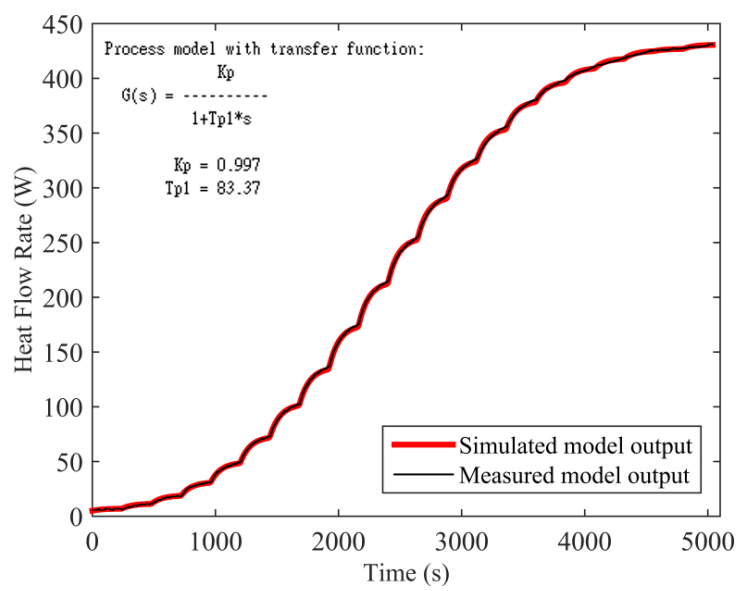

Fig. 14 Simulated model output of the precise heating system

\subsection{Precise Cooling System}

A precise cooling system is a VRF refrigeration system with a VFD compressor. By adjusting the compressor speed through the VFD, the cooling capacity of the refrigeration system can be controlled. The structure on the evaporator side of the cooling system is shown in Fig. 15. The evaporator uses a finned tube heat exchanger, which is selected because air is a good insulator with a low thermal conductivity. The analysis of the convection heat transfer equation reveals that increasing the convection heat transfer coefficient has a limited effect on the heat transfer. Therefore, increasing the heat transfer capability requires a larger heat exchange area to enhance the heat convection on the air side while reducing the thermal resistance. The condensing unit structure is shown in Fig. 16. It includes a VFD 
compressor, an electronic expansion valve, a condenser, and piping components.

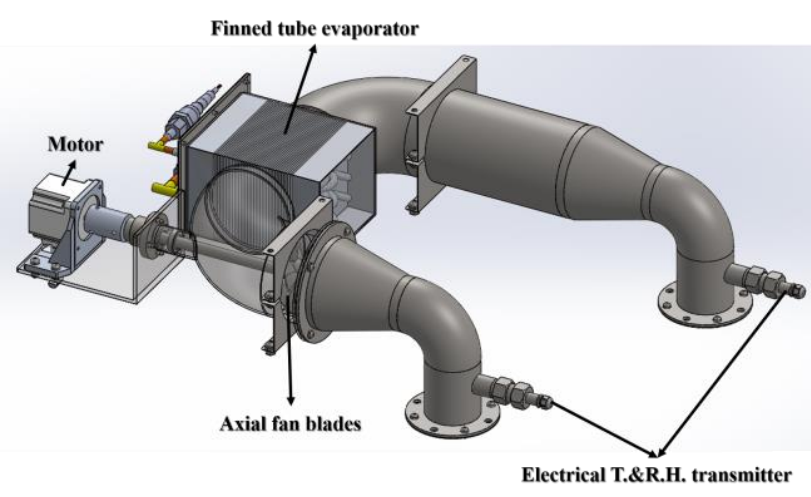

Fig. 15 Evaporating units of the precise cooling system

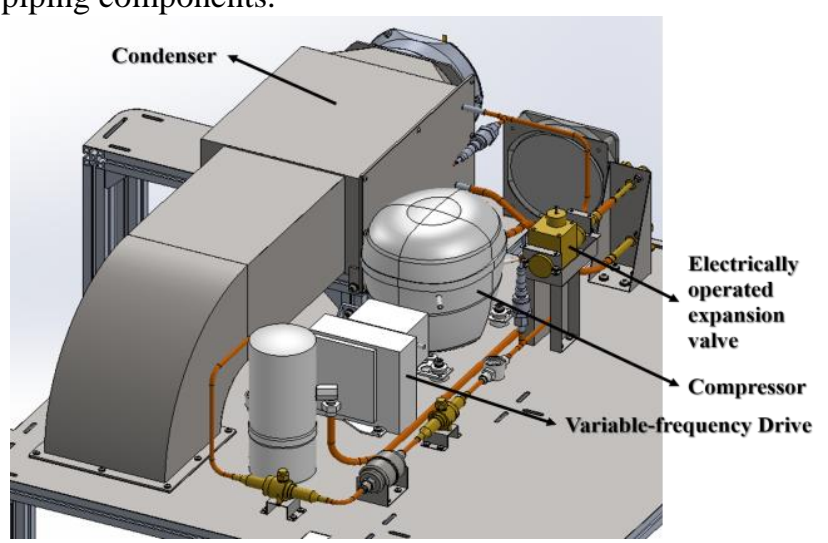

Fig. 16 Condensing units of the precise cooling system

The measured data from the precise cooling system are shown in Fig. 17. The blue line is the control percentage of compressor speed, and the red line is the system heat flow rate. A negative heat flow rate indicates the amount of heat that can be removed in unit time. Before 6600 seconds, the compressor operates at the lowest speed. After 6600 seconds, the line represents the heat flow rate of the cooling system in accordance with the control signal.

Observing the response characteristics, the model of the cooling system can be composed of a second-order process model and a first-order process model with nonlinear gain. The second-order process model is used to figure out how long the refrigeration system reaches the steady state, and the first-order process model with nonlinear gain for compressor speed change. The time constants of the model are 3045.1 seconds and 479.08 seconds individually by using the system identification tool as shown in Fig. 18. Because the longer time constant is 3045.1 seconds, the refrigeration system has to spend 15225.5 seconds for operating in steady state.

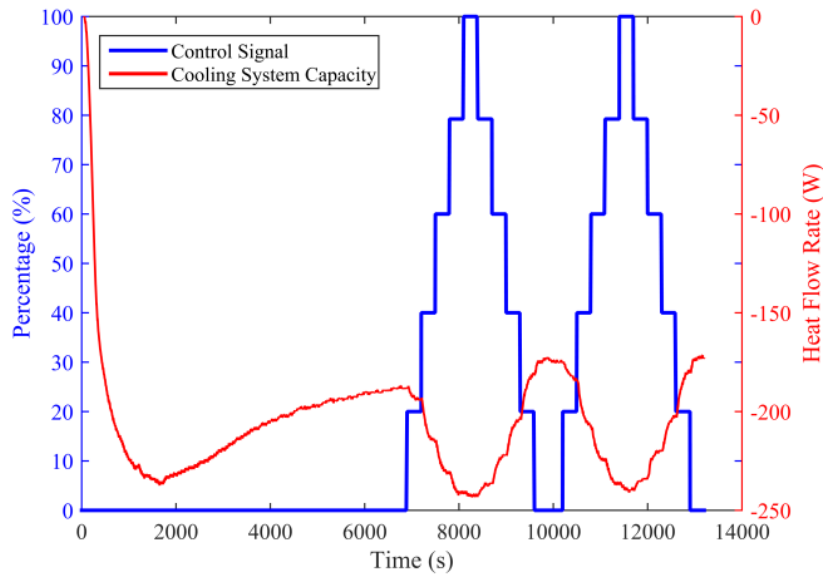

Fig. 17 Identification data of the precise cooling system

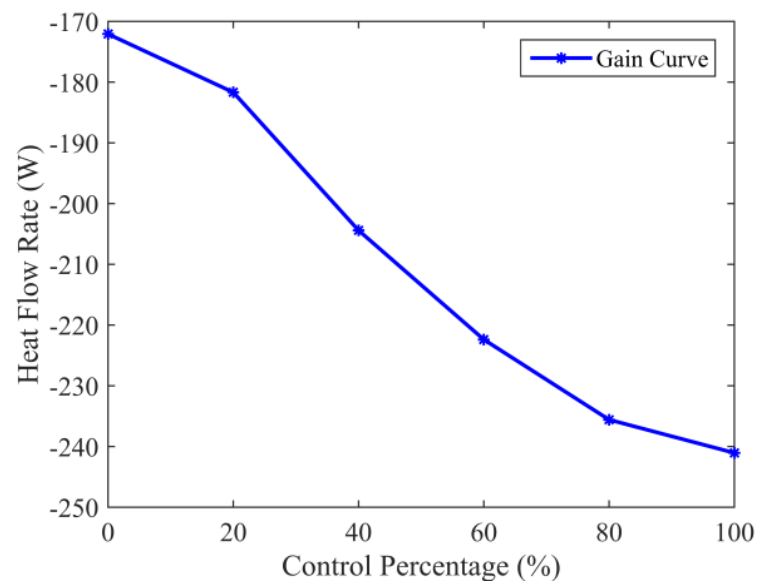

Fig. 19 Nonlinear gain of the cooling system in steady state

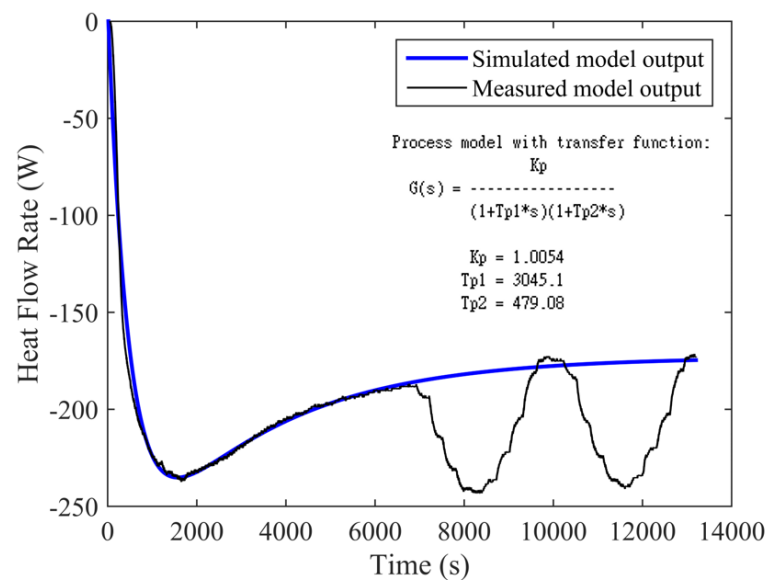

Fig. 18 Simulated model output when compressor is ON

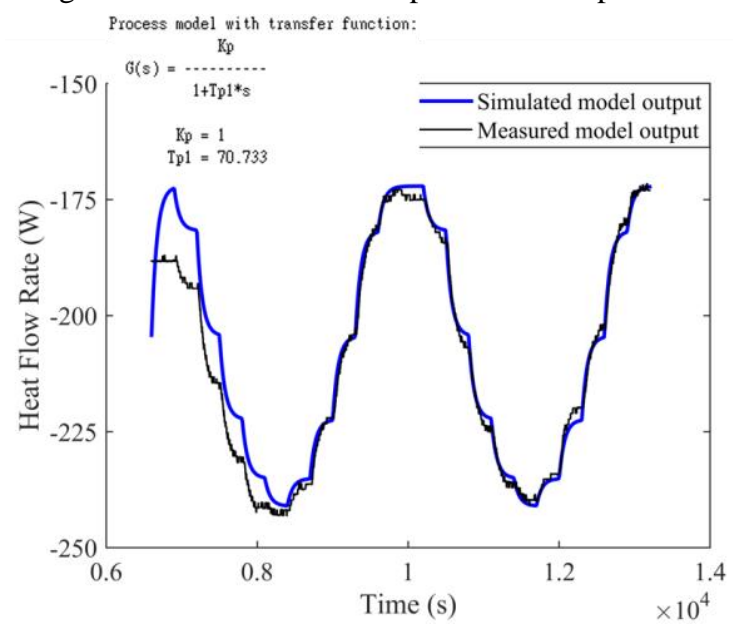

Fig. 20 Simulated model output of the precise cooling system 
Moreover, in steady state, the control percentage and the heat flow rate have a nonlinear relationship. Therefore, the gain curve in the steady state is as shown in Fig. 19. The time constant and response of the first-order process model can be obtained shown in Fig. 20. By excluding the section before it reaches steady state, the response mostly fit with the measured data, which indicates a satisfactory characteristic identification result for the cooling system.

\section{Experiments and Results}

After completing the system design and characteristic identification, the next step is to verify the feasibility of the sine wave temperature. The structure of the system used for verification is shown in Fig. 21. The cylindrical test chamber is in the middle, the precise heating system is on the left, the evaporator side of the precise cooling system is at the top, and the condenser unit is located at the bottom. The data measurement and control system consist of a PC with a National Instrument CompactDAQ and LabVIEW software. Before performing the feasibility test of the sinusoidal temperature, an experiment is fulfilled for the heat loss estimation. The feasibility test was conducted with triangle waves and sine waves from $5{ }^{\circ} \mathrm{C}$ to $45^{\circ} \mathrm{C}$ every period of 14400 seconds.
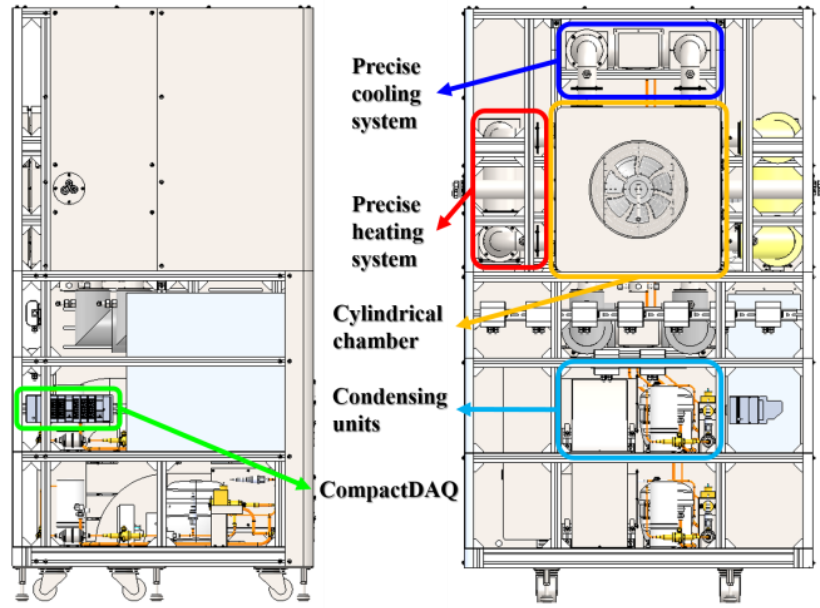

Fig. 21 Experimental setup for the triangle wave temperature and sine wave temperature

\subsection{Heat Loss Estimation and Sinusoidal Temperature Program Discussion}

The measured data for estimating the model of the heat loss are shown in Fig. 22. The blue line is the difference between the chamber temperature $T_{c h a}$ and the environment temperature $T_{e n v}$. The heat loss rate $\dot{Q}_{l o s s}$ as the red line is the difference between the supplied heat flow rate from the heating system $\dot{Q}_{\text {sup }}$ and the stored heat flow rate in the chamber $\dot{Q}_{r e q}$.

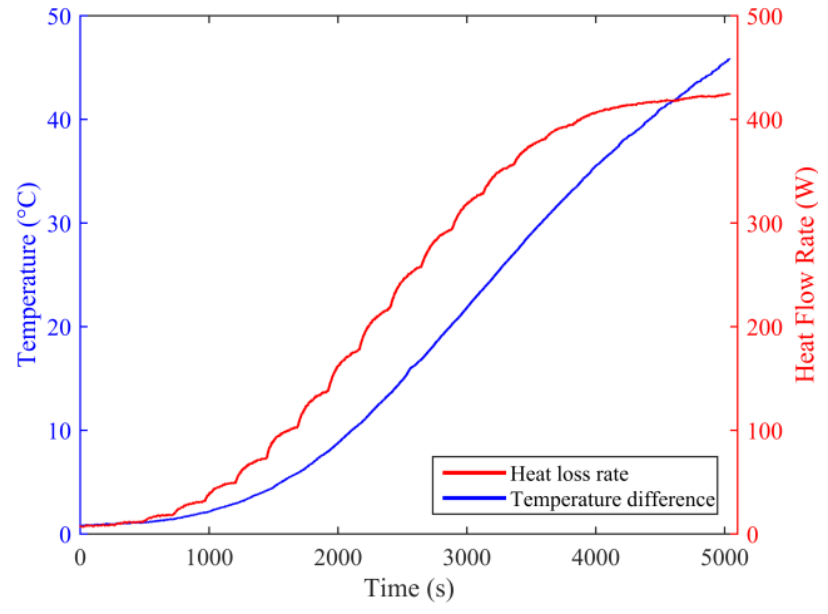

Fig. 22 Identification data for the heat loss model estimation

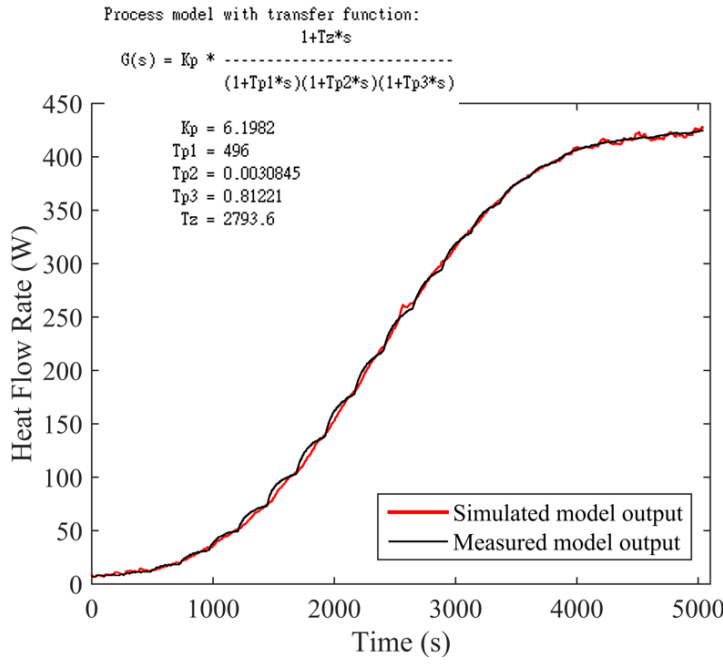

Fig. 23 Simulated output of the heat loss model

The model of the heat loss can be assumed as a third-order process model, becasue the wall structure is constructed 
of an inside cylindrical chamber, an insulation of glass fiber blanket, and an outside cuboid casing. Using the system identification tool, the parameters and response of the simulated model of the heat loss are obtained as shown in Fig. 23. The simulated response almost met the measured response, which exhibits an adequate identification result.

At first the temperature of sine wave program was designed for $-20-150{ }^{\circ} \mathrm{C}$ with 5667 seconds of period, and the heat loss rate from the walls was estimated by a theoretical model of heat loss shown as the red solid line in the Fig. 24. According to the required heat flow rate as the green solid line in Fig. 24, the precise heating system and cooling system were constructed above.

After getting the experimental model of heat loss as Fig. 23 and recalculating the true required heat flow rate for $-20-150{ }^{\circ} \mathrm{C}$ of sine wave program as shown in Fig. 25, the heat loss rate of theoretical model has been underestimated. Because the maximum of true required heating capacity is about $1750 \mathrm{~W}$ and the maximum of true required cooling capacity is around $1200 \mathrm{~W}$, both of them are such higher than the designed values before. However, the feasibility of temperature sine wave test should be completed and the temperature sine wave program needs redrawing.

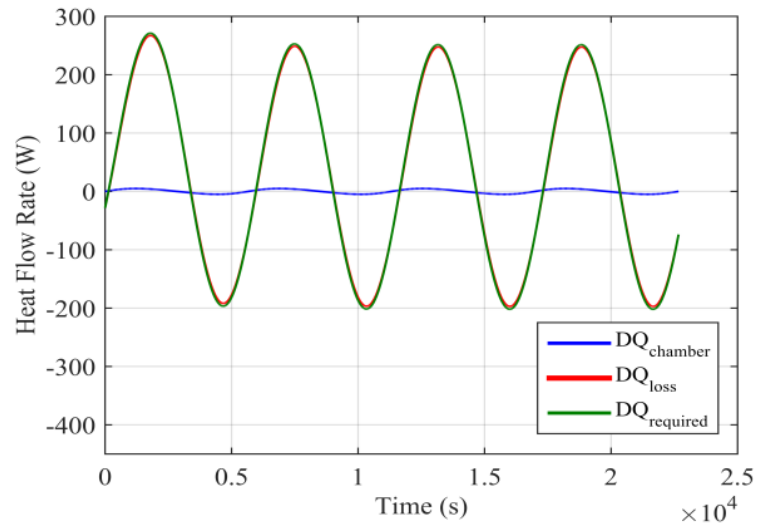

Fig. 24 Required heat flow rate by theoretical model

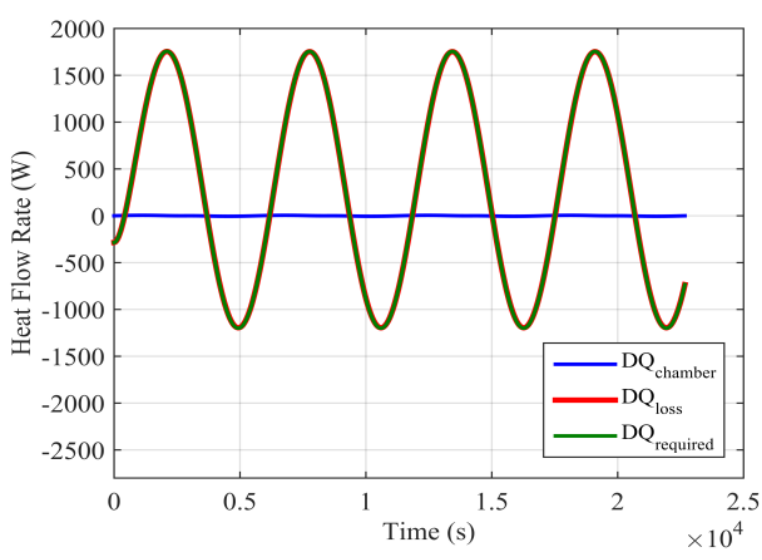

Fig. 25 True heat flow rates by the experimental model

The temperature range and period of sine wave program are limited by operating temperature range, heat flow rate, and heat flow acceleration of the precise actuators. Furthermore, decreasing the temperature range can reduce the heat flow rate but to increase the heat flow acceleration, on the other hand, extending the period can lessen the heat flow rate and heat flow acceleration simultaneously. In addition, the calculation of heat flow acceleration is the differential in heat flow rate at specific time. So the heat flow acceleration of the precise heating system can be figured as Fig. 26 with the heat flow rate of the identification data as Fig. 12, and the heat flow acceleration of the precise cooling system is shown as Fig. 27 by using the data of heat flow rate in Fig. 17.

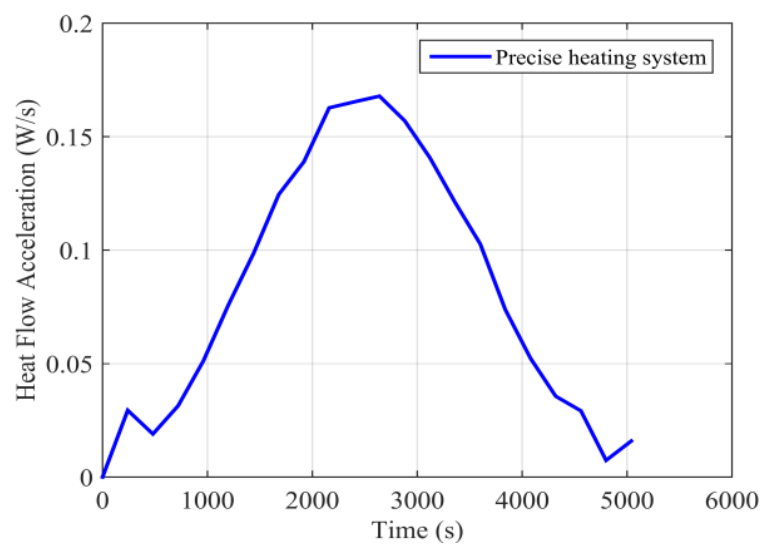

Fig. 26 Heat flow acceleration of the precise heating system

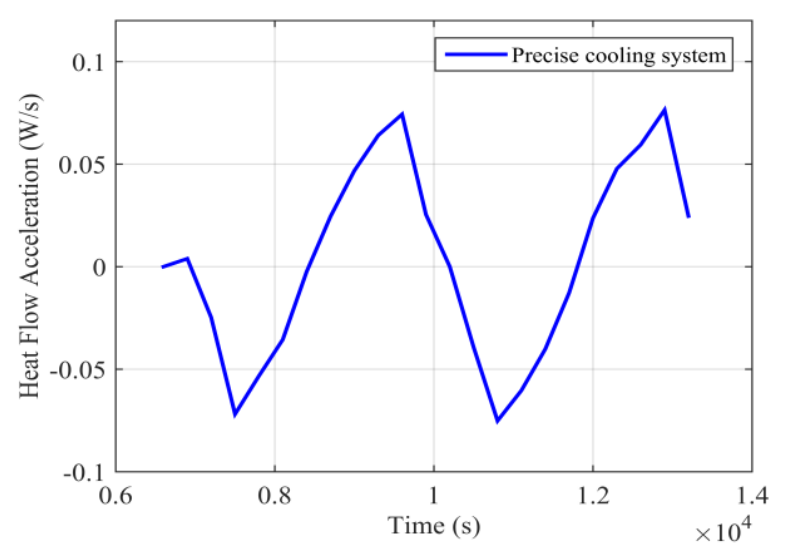

Fig. 27 Heat flow acceleration of the precise cooling system

Upon the lowest operating temperature of the chamber is around $0{ }^{\circ} \mathrm{C}$ shown as Fig. 28 , and the maximum of heat flow accelerations of the heating and cooling system are about $0.17 \mathrm{~W} / \mathrm{s}$ and $-0.075 \mathrm{~W} / \mathrm{s}$ respectively. Consequently, the range of temperature sine wave program is compromised from $-20-150{ }^{\circ} \mathrm{C}$ down to $5-45^{\circ} \mathrm{C}$ and the period is extended from 5667 seconds to 14400 seconds as Fig. 29. The required heat flow rates are confirmed less than the maximum capacities of precise actuators as shown in Fig. 30. Also, the heat flow accelerations almost meet the limits of the precise actuators shown in Fig. 31. 


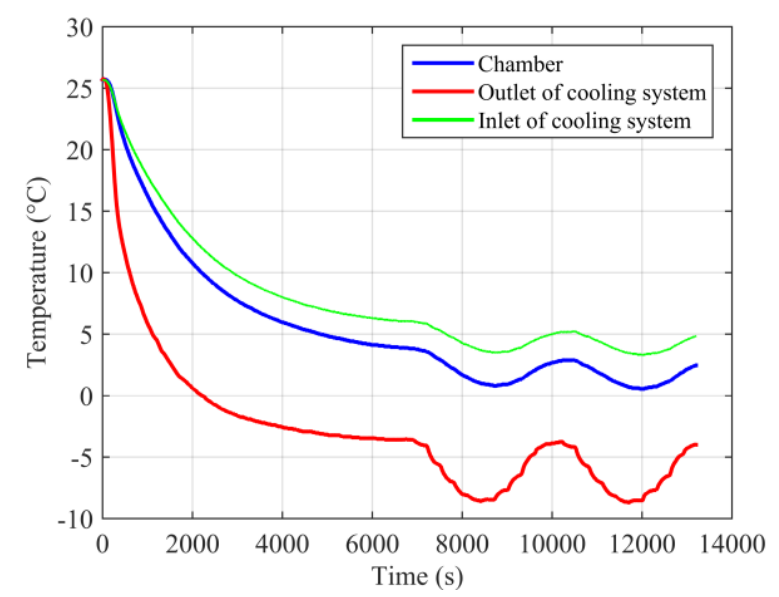

Fig. 28 Temperatures of identification data of cooling system

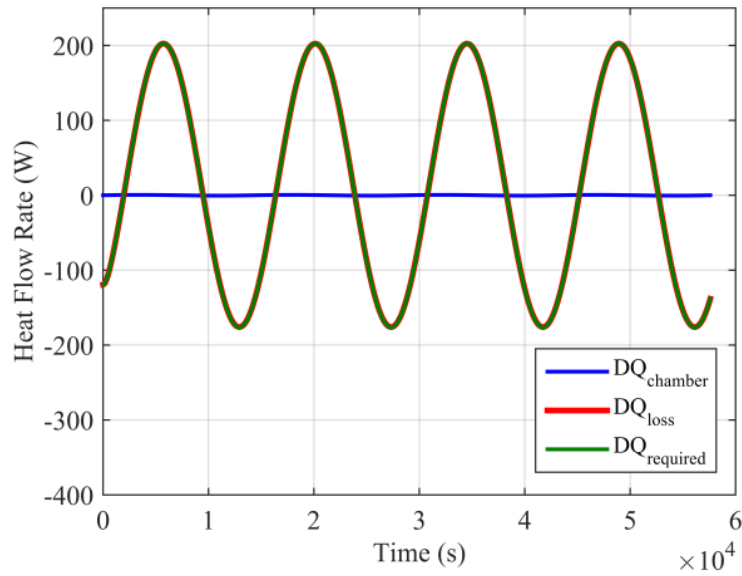

Fig. 30 Required heat flow rate confirmation

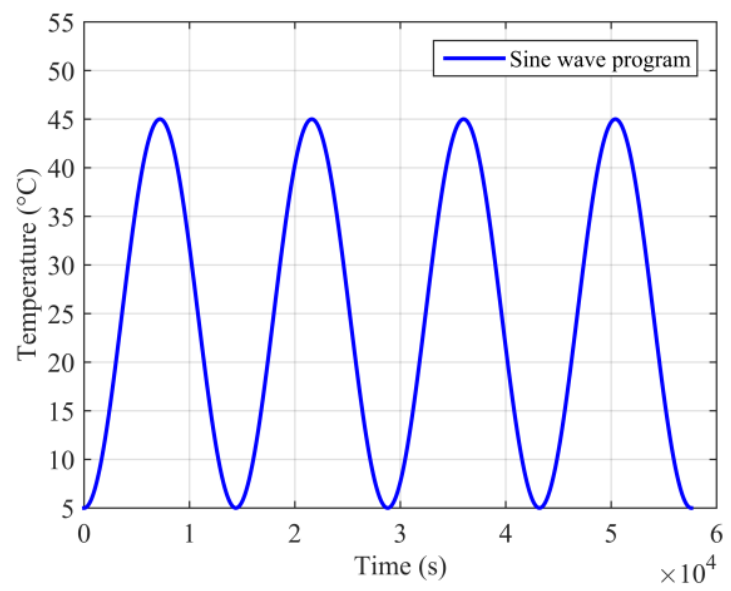

Fig. 29 Compromised sine wave program

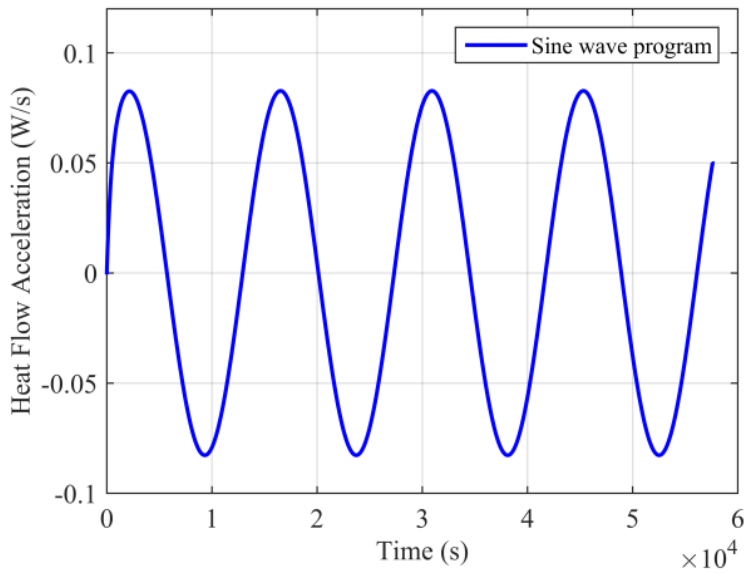

Fig. 31 Heat flow acceleration confirmation

\subsection{Triangle Wave Temperature program}

The triangle wave test result is shown in Fig. 32. The black line is the programmed value, and the red line is the measured air temperature. In the first 600 seconds, the temperature is maintained at $5^{\circ} \mathrm{C}$, followed by 4 periods of triangle waves. The two curves closely match each other. The error between the measured value and the programmed value is shown in Fig. 33. The error generally remains within $\pm 0.3^{\circ} \mathrm{C}$. Only at the maximum and minimum, when the slope of the temperature drastically changes, the error approaches $\pm 0.5^{\circ} \mathrm{C}$, which indicates that the triangle wave temperature program is feasible.

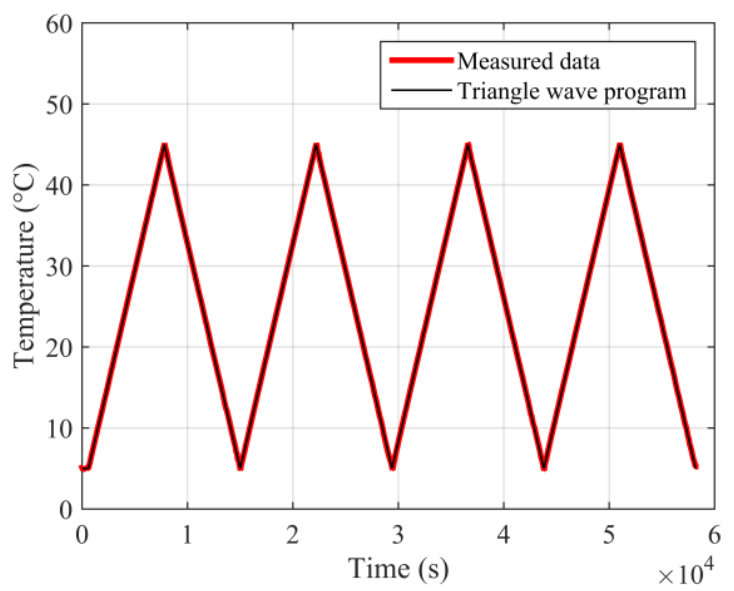

Fig. 32 Measured data of the triangle wave test

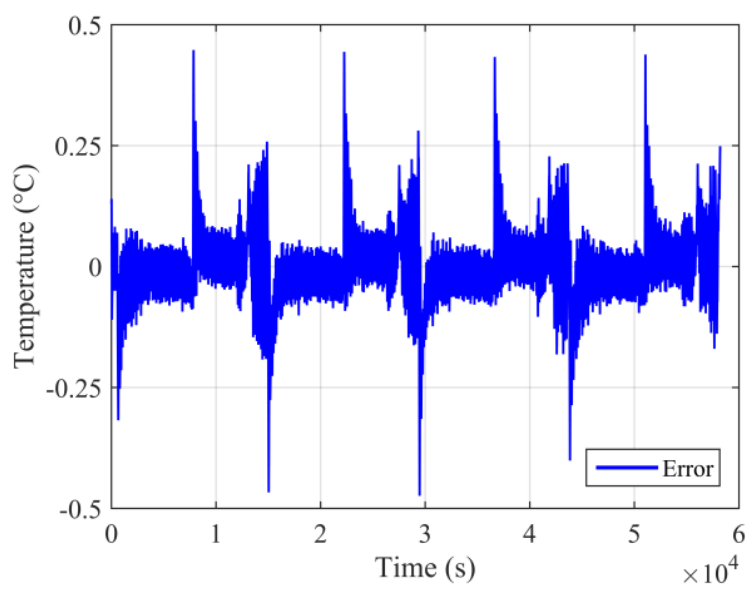

Fig. 33 Temperature error of the triangle wave test 


\subsection{Sine Wave Temperature program}

The sine wave temperature experiment result is shown in Fig. 34. The black line is the programmed value, and the red line is the measured air temperature. Between 0 and 600 seconds, the temperature is held at $5^{\circ} \mathrm{C}$, followed by 4 periods of sine waves after 600 seconds. The measured temperature and the programmed sine wave value are nearly identical, and the error between the two is shown in Fig. 35. Except for one point in time when the error exceeds $-0.25^{\circ} \mathrm{C}$, all errors are within $\pm 0.25^{\circ} \mathrm{C}$, which proves the usability of the sine wave temperature program in an environmental test.

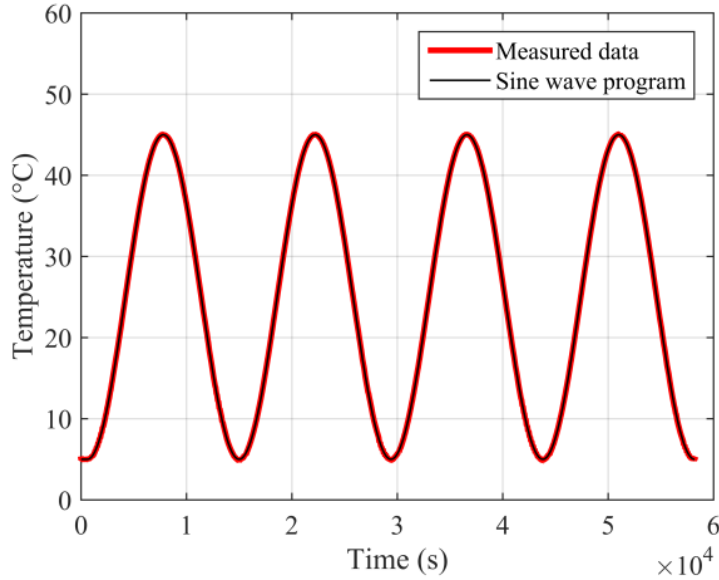

Fig. 34 Measured data of the sine wave test

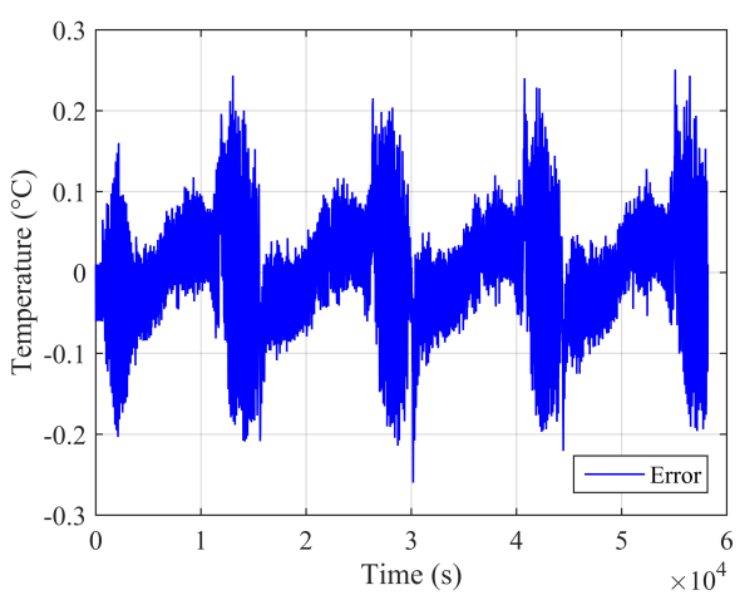

Fig. 35 Temperature error of the sine wave test

\section{Conclusion}

Based on the experiment results, the IPCM is proven to provide an environmental chamber the sine wave temperature under the no-load condition with an error smaller than $\pm 0.25^{\circ} \mathrm{C}$. Regarding the cycle time, the independent flow loops structure uses stainless steel pipes with a thickness of $3 \mathrm{~mm}$, which causes excessive heat loss and a longer time constant in the precise cooling system. To shorten the cycle time, a material with a lower heat capacity is necessary to replace stainless steel. Moreover, to realize a dual sine wave program in temperature and relative humidity, a precise humidifying system and a precise dehumidifying system must be designed.

\section{Acknowledgment}

The authors would like to express deep gratitude to Gong Bu Design Company, Ltd. for the financial and technical support. In consequence, Gong $\mathrm{Bu}$ Design Company, Ltd. reserves all rights to the patent of the Intelligent Predetermined Control Method, Patent TW I476555 B.

\section{References}

Huang, B. J., Liao, Y. C., and Kuo, T. C., Study of a new environmental chamber design, Applied Thermal Engineering, Vol. 27, No. 11-12 (2007), pp. 1967-1977, DOI: 10.1016/j.applthermaleng.2006.12.010.

Hung, S. S., Lin, A. C. Y., and Chen, Y. H., Developing the intelligent predetermined control method for a new temperature and humidity chamber: A Case study for rising temperature under constant relative humidity, 2015 IEEE Advanced Information Technology, Electronic and Automation Control Conference (2015), pp. 423-427, DOI: 10.1109/IAEAC.2015.7428588.

Hyland, R. W. and Wexler, A., Formulations for the thermodynamic properties of dry air from $173.15 \mathrm{~K}$ to $473.15 \mathrm{~K}$, and of saturated moist air from $173.15 \mathrm{~K}$ to $372.15 \mathrm{~K}$, at pressures to $5 \mathrm{MPa}$, ASHRAE Transactions, Vol. 89(2A) (1983a), pp. 520-535.

Hyland, R. W. and Wexler, A., Formulations for the thermodynamic properties of the saturated phases of $\mathrm{H} 2 \mathrm{O}$ from 
173.15 K to 473.15 K, ASHRAE Transactions, Vol. 89(2A) (1983b), pp. 500-519.

Ishida, T., New JTM standards for temperature test chambers - Methods of testing and indicating performance, ESPEC Technology Report, No. 24 (2007), pp. 18-28.

Jiang, Y., Ge, T. S., Wang, R. Z., and Huang, Y., Experimental investigation on a novel temperature and humidity independent control air conditioning system - Part II: Heating condition, Applied Thermal Engineering, Vol. 73, No. 1 (2014), pp. 775-783, DOI: 10.1016/j.applthermaleng.2014.08.030.

Li, N., Xia, L., Shiming, D., Xu, X., and Chan, M. Y., On-line adaptive control of a direct expansion air conditioning system using artificial neural network, Applied Thermal Engineering, Vol. 53, No. 1 (2013), pp. 96-107, DOI: 10.1016/j.applthermaleng.2013.01.008.

Li, Z., Xu, X., Deng, S., and Pan, D., A novel neural network aided fuzzy logic controller for a variable speed (VS) direct expansion (DX) air conditioning (A/C) system, Applied Thermal Engineering, Vol. 78 (2015), pp. 9-23, DOI: 10.1016/j.applthermaleng.2014.12.030.

Li, Z., Chen, J. B., Yu, H. Z., and Cui, L. C., The development and experimental performance evaluation on a novel household variable refrigerant flow based temperature humidity independently controlled radiant air conditioning system, Applied Thermal Engineering, Vol. $122 \quad$ (2017), pp. 245-252, DOI: 10.1016/j.applthermaleng.2017.04.056.

Lopez-Sanz, J., Ocampo-Martinez, C., Alvarez-Florez, J., Moreno-Eguilaz, M., Ruiz-Mansilla, R., Kalmus, J., Gräeber, M., and Lux, G., Nonlinear model predictive control for thermal management in plug-in hybrid electric vehicles, IEEE Transactions on Vehicular Technology, Vol. 66, No. 5 (2017), pp. 3632-3644, DOI: 10.1109/TVT.2016.2597242.

Nachidi, M., Benzaouia, A., and Tadeo, F., Temperature and humidity control in greenhouses using the Takagi-Sugeno fuzzy model, Proceedings of the 2006 IEEE International Conference on Control Applications (2006), pp. 2150-2154, DOI: 10.1109/CACSD-CCA-ISIC.2006.4776973.

Oldewurtel, F., Jones, C. N., Parisio, A., and Morari, M., Stochastic model predictive control for building climate control, IEEE Transactions on Control Systems Technology, Vol. 22, No. 3 (2014), pp. 1198-1205, DOI: 10.1109/TCST.2013.2272178.

Rentel-Gomez, C. and Velez-Reyes, M., Decoupled control of temperature and relative humidity using a variable-air-volume HVAC system and non-interacting control, Proceedings of the 2001 IEEE International Conference on Control Applications (2001), pp. 1147-1151, DOI: 10.1109/CCA.2001.974026.

Sturzenegger, D., Gyalistras, D., Morari, M., and Smith, R. S., Model predictive climate control of a Swiss office building: Implementation, results, and cost-benefit analysis, IEEE Transactions on Control Systems Technology, Vol. 24, No. 1 (2016), pp. 1-12, DOI: 10.1109/TCST.2015.2415411.

$\mathrm{Su}, \mathrm{Y}$., Xu, L., and Li, D., Adaptive fuzzy control of a class of MIMO nonlinear system with actuator saturation for greenhouse climate control problem, IEEE Transactions on Automation Science and Engineering, Vol. 13, No. 2 (2016), pp. 772-788, DOI: 10.1109/TASE.2015.2392161.

Tashtoush, B., Molhim, M., and Al-Rousan, M., Dynamic model of an HVAC system for control analysis, Energy, Vol. 30, No. 10 (2005), pp. 1729-1745, DOI: 10.1016/j.energy.2004.10.004.

Yang, Q., Zhu, J., Xu, X., and Lu, J., Simultaneous control of indoor air temperature and humidity for a chilled water based air conditioning system using neural networks, Energy and Buildings, Vol. 110 (2016), pp. 159-169, DOI: 10.1016/j.enbuild.2015.10.034.

Yordanova, S., Merazchiev, D., and Jain, L., A two-variable fuzzy control design with application to an air-conditioning system, IEEE Transactions on Fuzzy Systems, Vol. 23, No. 2 (2015), pp. 474-481, DOI: 10.1109/TFUZZ.2014.2312979.

Zeng, X. and Yu, C., Multivariable IMC-PID within air-conditioned room temperature and relative humidity control system, Proceedings of the 33rd Chinese Control Conference (2014), pp. 3609-3613, DOI: 10.1109/ChiCC.2014.6895539. 